\title{
Microplastic Intake, Its Biotic Drivers, and Hydrophobic Organic Contaminant Levels in the Baltic Herring
}

\author{
Martin Ogonowski ${ }^{1,2,3 *}$, Viktoria Wenman ${ }^{1}$, Andreas Barth ${ }^{4}$, Evelyne Hamacher-Barth ${ }^{4}$, \\ Sara Danielsson ${ }^{5}$ and Elena Gorokhova ${ }^{1 *}$ \\ ${ }^{1}$ Department of Environmental Science and Analytical Chemistry, Stockholm University, Stockholm, Sweden, ${ }^{2}$ Department of \\ Aquatic Resources, Institute of Freshwater Research, Swedish University of Agricultural Sciences, Drottningholm, Sweden, \\ ${ }^{3}$ AquaBiotaWater Research, Stockholm, Sweden, ${ }^{4}$ Department of Biochemistry and Biophysics, Stockholm University, \\ Stockholm, Sweden, ${ }^{5}$ Swedish Museum of Natural History, Department of Environmental Science and Monitoring, \\ Stockholm, Sweden
}

OPEN ACCESS

Edited by:

Jérôme Cachot,

Université de Bordeaux, France

Reviewed by:

Claudia Mieiro,

University of Aveiro, Portugal

André Ricardo Araújo Lima,

Federal University of

Pernambuco, Brazil

Stefania Gorbi,

Marche Polytechnic University, Italy

*Correspondence:

Martin Ogonowsk

martin.ogonowski@slu.se

Elena Gorokhova

elena.gorokhova@aces.su.se

Specialty section:

This article was submitted to

Marine Pollution,

a section of the journal

Frontiers in Environmental Science

Received: 03 June 2019

Accepted: 28 August 2019

Published: 12 September 2019

Citation:

Ogonowski M, Wenman V, Barth A

Hamacher-Barth E, Danielsson S and

Gorokhova E (2019) Microplastic

Intake, Its Biotic Drivers, and

Hydrophobic Organic Contaminant

Levels in the Baltic Herring.

Front. Environ. Sci. 7:134.

doi: 10.3389/fenvs.2019.00134
It is commonly accepted that microplastic (MP) ingestion can lead to lower food intake and bioaccumulation of hydrophobic organic contaminants (HOCs) in aquatic organisms. However, causal links between MP and contaminant levels in biota are poorly understood and in situ data are very limited. Here, we investigated whether HOC concentrations in herring muscle tissue (Clupea harengus membras) are related to MP ingestion using fish caught along the West coast of the Baltic Sea. The MP occurrence exhibited a large geographic variability, with MP found in $22.3 \%$ of the fish examined, and the population average being $0.9 \mathrm{MP}$ ind $^{-1}$. However, when only individuals containing MP were considered, the average MP burden was $3.9 \mathrm{MP}$ ind $^{-1}$. We also found that MP burden decreased with reproductive stage of the fish but increased with its body size. To predict MP abundance in fish guts, we constructed a mass-balance model using literature data on MP in the water column and physiological rates on ingestion and gut evacuation for clupeids of a similar size. The model output was in agreement with the observed values, thus supporting the validity of the results. Contaminant concentrations in the muscle tissue varied substantially across the study area but were unrelated to the MP levels in fish, suggesting a lack of direct links between the levels of HOCs and MP ingestion. Thus, despite their ubiquity, MP are unlikely to have a measurable impact on food intake or the total body burden of hydrophobic contaminants in Baltic herring.

Keywords: microplastic, Baltic sea, herring, hydrophobic organic contaminants, marine monitoring

\section{INTRODUCTION}

Plastic debris, including microplastics ( $\mathrm{MP}<5 \mathrm{~mm}$ ), can be ingested by aquatic animals across several trophic levels (Cole et al., 2013; Lusher et al., 2013, 2015). Due to the importance of commercial fish and shellfish species for human consumption, the ingestion and presence of MP in these animals has become a matter of concern (EFSA Panel on Contaminants in the Food Chain (CONTAM), 2016). To address this concern and to provide a quantitative assessment of MP ingestion in various fish species, an active research is ongoing (Foekema et al., 2013; Lusher et al., 2013; Rummel et al., 2016; Beer et al., 2018; Budimir et al., 2018; Markic et al., 2019). 
A commonly held paradigm states that MP ingestion can lead to decreased nutritional status (Cole et al., 2015; Ogonowski et al., 2016) and bioaccumulation of hydrophobic organic chemicals (HOCs) (Rochman et al., 2013; Wardrop et al., 2016) that sorb to the MP particles in the water and desorb in the gut lumen (Rochman et al., 2014). However, some experimental and modeling studies indicate that plastic polymers could also have a net cleaning effect acting as passive samplers while in the digestive system and thereby relieve the animals of HOCs (Gouin et al., 2011; Gerdes et al., 2019; Mohamed Nor and Koelmans, 2019). The relative importance of microplastics as vectors for contaminant transport remains unresolved, possibly also due to the lack of field data linking HOC concentrations in biota to ingested MP in ecologically relevant settings.

Here, we studied MP ingestion by Baltic Sea herring (Clupea harengus membras L.), a commercially exploited fish and a keystone species in the Baltic food web. Being facultative pelagic filter-feeders (Huse and Toresen, 1996), herring stand a high risk of ingesting MP along with zooplankton prey and hence accumulating MP-associated contaminants. It is also a sentinel species in the Swedish National Monitoring Program for Contaminants in Marine Biota (SNMPC) and, thus, a potential indicator species for MP monitoring in the Baltic Sea (Beer et al., 2018).

If MP ingestion indeed contributes significantly to HOC bioaccumulation in contaminated environments, then one would see a positive correlation between the amount of MP ingested over time and HOC concentrations in the animals. However, there are no reliable methods to estimate accumulated MP exposure using field samples of fish, because MP do not accumulate to any significant extent in their digestive system (Jovanović, 2017). Although gut contents reflect only a recent ingestion history, the MP burden determined by gut content analysis is commonly used as a reflection of the feeding habits and habitats of the fish. Another area of concern with respect to the interpretation of MP counts in environmental samples, including fish guts, is analytical accuracy and reliability of MP extraction, and determination (Dehaut et al., 2016). Therefore, to increase the reliability of the MP gut content data, it is important to verify whether the recorded MP body burden is within ecologically plausible rates of ingestion and gut evacuation. To compare the observed MP abundance in the fish gut with the intake that can be expected given the MP abundance in the water column, and gut evacuation that can be expected given the food intake, a mass-balance modeling approach can be used. Here, we applied such modeling using literature-derived parameters on clupeid feeding and food processing as well as ambient MP concentrations, to estimate MP burden in the herring with a body size similar to those in our collection. To further evaluate the ecological plausibility of our MP-quantification, we also investigated the relationship between several biological parameters and MP ingestion.

Once the plausibility of our MP measurements was confirmed, we tested the hypothesis that HOC concentrations in the fish muscle measured by SNMPC were unrelated to the weightspecific MP gut content. Hence, the objectives and workflow of this study were: (1) to quantify MP ingestion by Baltic herring,

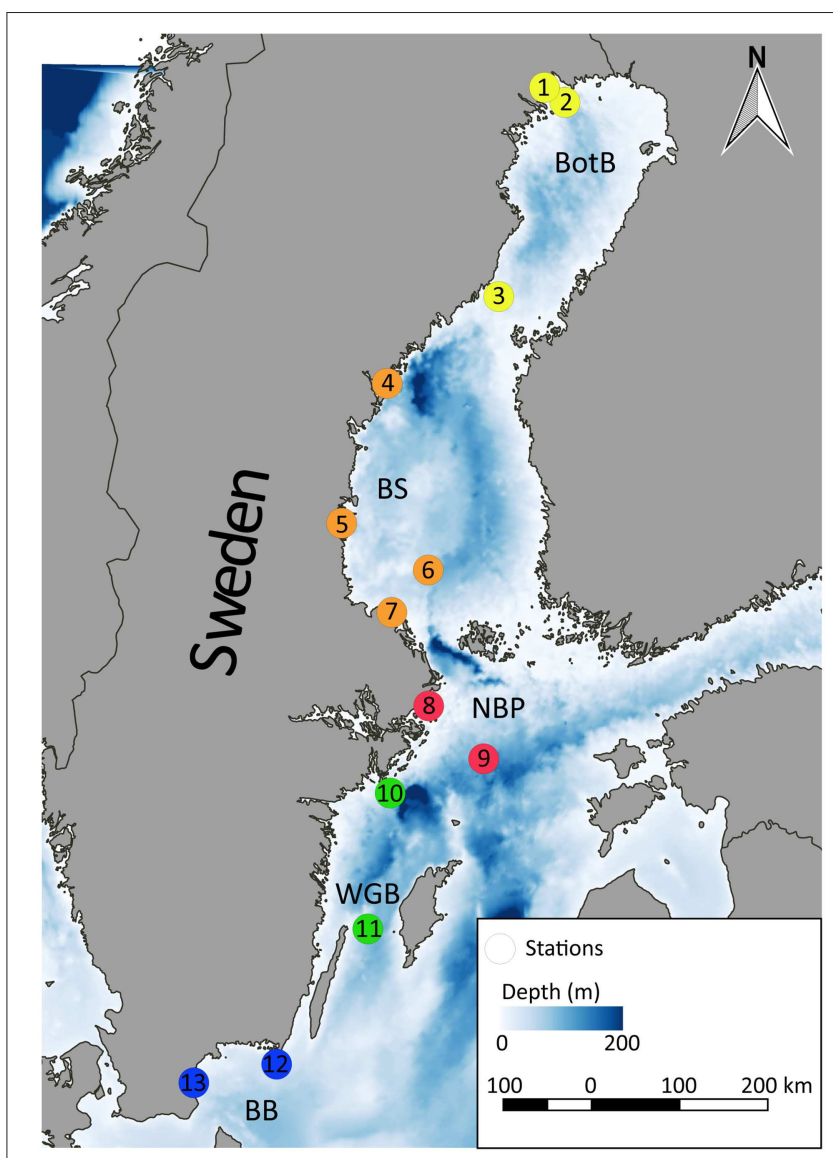

FIGURE 1 | Sampling sites within the Swedish National Monitoring Program for Contaminants in Marine Biota included in this study, BotB: Bothnian Bay (yellow), BS: Bothnian Sea (orange), NBP: Northern Baltic Proper (red), WGB: Western Gotland Basin (green), and BB: Bornholm Basin (blue). 1:

Rånefjärden, 2: Harufjärden, 3: Holmöarna, 4: Gaviksfjärden, 5:

Långvindsfjärden, 6: Bothnian Sea, offshore site, 7: Ängsskärsklubb, 8: Lagnö, 9: Baltic proper, offshore site, 10: Landsort, 11: Byxelkrok, 12: Utlängan, and 13: Western Hanö Bight.

(2) to assess whether the measured MP burden is ecologically plausible, and (3) to establish whether the levels of HOC are related to the measured MP burden in fish.

\section{MATERIALS AND METHODS}

\section{Fish Collection and Sample Characteristics}

The Baltic herring used for our analyses were collected by SNMPC conducted by the Swedish Museum of Natural History (Stockholm, Sweden). To avoid possible bias by known point sources, we randomly selected 130 specimens that had been collected at 13 reference monitoring stations $(n=10$ per station, Figure 1), thus covering a sufficient geographical area that would provide a representative range of $\mathrm{HOC}$ and $\mathrm{MP}$ exposure for the analysis.

The sex ratio of the selected fish was $\sim 50: 50$ and uniform across sampling sites. The individuals were 3-7 years old, with a total length of $173 \pm 18 \mathrm{~mm}$ and body weight $35 \pm 12 \mathrm{~g}$ 
wet weight (mean $\pm \mathrm{SD}$ ). The reproductive phase determined by gametocytic maturity was classified on a five-degree scale according to Bucholtz et al. (2008) and included deformed gonads (stage 1), post spawned individuals (stage 2), juveniles (stage 3), individuals with developing gonads (stage 4), and fish with mature gonads (stage 5).

Each fish was dissected, and the muscle tissues taken from the middle dorsal muscle layer were used for HOC analysis, whereas the entire gastrointestinal tract (GIT) was used for the MP analysis. All sampling was performed according to standard procedures (TemaNord, 1995) employed by SNMPC. After dissecting, each individual GIT was packed in aluminum foil to avoid cross-contamination. All GIT samples were immediately frozen at $-20^{\circ} \mathrm{C}$ and stored until MP analysis at the Department of Environmental Science and Analytical Chemistry, Stockholm University, Sweden.

\section{MP Quantification in the Gastrointestinal Tract of Fish}

To quantify the number of MP ingested by the herring (objective 1), each GIT was placed in a glass Petri dish, opened with surgical scissors, and rinsed with deionized, particle-free water. Using a stereo microscope, the bolus was examined, and any items resembling MP were extracted by stainless steel pincers and transferred to clean Eppendorf tubes filled with milli-Q water. The appearance of the putative MP was recorded and each particle was categorized according to its shape (fiber or fragment) and color. Hereafter, the number of MP per individual fish is referred to as MP burden. A subsample $(n=20)$ of the putative MP was photographed using digital camera (Canon 5D mark III) fitted to a Leica DMBR bright field microscope (Leitz, Germany). The length (fibers) or largest diameter (fragments) was measured using the segmented measurement tool in Image J (Schneider et al., 2012).

To relate HOC concentration in the muscle tissue to MP intake by the fish, the fish size must be taken into account when expressing MP counts. Moreover, in our collection, the bolus size varied considerably among the individual fish and geographical areas (Table 2), indicating variability in feeding activity shortly before sampling and/or spontaneous gut evacuation that might have been related to stress during the sampling. To account for variability in bolus size and the corresponding variation in the observed MP burden, we normalized individual MP counts to the gut fullness. The latter was assessed by visual observation on a five-step semi-quantitative scale: 0 (empty gut, no food items), $0.25,0.5,0.75$, or 1 (full gut). The obtained values were further normalized to the individual body weight and termed weightspecific MP burden [number of MP / (gut fullness $\times$ body weight) ( $g$ wet weight)]. This normalization approach allowed for relating HOC concentrations in the fish to the expected MP burden in the GIT on a weight basis.

The following polymer identification scheme was applied. First, to identify whether the putative MP were synthetic polymers, we followed the recommendations of Hidalgo-Ruz et al. (2012). Particles $1-5 \mathrm{~mm}$ in diameter were recorded and classified as MP, if all the following criteria were met: (i) uniform, unnaturally bright or of an unnatural color, (ii) lack of organic structures, and (iii) uniform diameter over the entire length of a fiber. Second, to test the accuracy of the visual identification, all samples containing putative MP (i.e., the gut contents of 44 individual fish) were analyzed using Fourier transform infrared spectroscopy (FTIR) according to recent quality assurance guidelines (Hermsen et al., 2018). However, due to significant losses during initial handling, the particle recovery was low and only 61 microparticles were analyzed by FTIR. Third, MP-validation was performed by comparing the sample spectra to a published reference database (Primpke et al., 2018). The Hit Quality Index (HQI) was used to determine whether a sample spectrum matched any spectra in the database. The HQI-threshold for a match was set at $70 \%$ similarity (Thompson et al., 2004). A detailed description of the data preparation of sample spectra and sample classification is provided in Supporting Information 1.1 and Figure S1.

\section{FTIR Analysis}

The infrared spectra were recorded at $4 \mathrm{~cm}^{-1}$ resolution with a Bruker Vertex 70 FTIR instrument that was equipped with a Bruker Platinum attenuated reflection (ATR) unit. Data were recorded on both sides of the center burst of the interferogram during forward and backward movement of the interferometer mirror. A zero filling factor of 2 was used and the spectra were apodized with a Blackman-Harris 3-term function. The spectra for samples 1-6 (Table S1) were recorded using an $\mathrm{HgCdTe}$ detector, 100 sample scans were recorded and the scanning time was $22 \mathrm{~s}$. The spectra for samples 7-61 (Table S1) were recorded using a DTGS detector, 364 sample scans were recorded within $300 \mathrm{~s}$ scanning time. Individual particles were placed on the diamond crystal of the ATR unit and pressed onto the crystal with a piston. Prior to each measurement, the crystal was cleaned with $99 \%$ ethanol.

\section{Controls and Blanks}

To minimize contamination by airborne particles during the examination, the dissections were performed under a Fumex local extractor (Wesch et al., 2016); each sample being analyzed for $10 \mathrm{~min}$. A Petri dish filled with filtered deionized water was placed next to a test sample to serve as a blank for the quantification and characterization of potential contamination during the analysis. When working with samples, a cotton lab coat, and gloves were used: moreover, the type and color of clothing were recorded to enable contamination back-tracing. All procedural blanks contained particles (mainly single fibers) of unknown origin. However, all these particles were $<1 \mathrm{~mm}$ and thus did not contribute to the MP counts used in the statistical analysis. If quantifiable amounts of blank contamination with particles $>1 \mathrm{~mm}$ were to be found, such samples would be excluded from any further analyses.

\section{Chemical Analysis}

Following the guidelines of the Swedish National Monitoring Program for Contaminants in Marine Biota, the muscle samples were analyzed for polychlorinated biphenyls (PCB 28, 52, 101, $118,138,153$, and 180), organochlorine pesticides (DDE, DDD, 
DDT, $\mathrm{HCB}, \mathrm{AHCH}, \mathrm{BHCH}$, and Lindane), and polybrominated flame-retardants (BDE 28, 47, 99, 100, 153, 154, and HBCD). For stations 2, 7, and 9-11 (Figure 1), $10 \mathrm{~g}$ of muscle tissue from individual fish were used, whereas $1 \mathrm{~g}$ samples of muscle tissue from 10 individuals were pooled for samples originating from stations 1, 3-6, 8, and 12-13 (Figure 1). An overview of the analyzed contaminants and their average concentrations in herring muscle tissue are provided in Table 1, while details of the analytical procedures and quality assurance practices used by SNMPC are provided elsewhere (Bignert et al., 2016).

\section{Data Analysis and Statistics Relationships Between Biological Factors, Geography, and Ingested Microplastic}

We used generalized additive models (GAM) in package $m g c v$ to examine relationships between specific biological variables (weight, gut fullness, age, and reproductive phase) and MP burden (objective 2). Sea basin was used as a fixed factor since the inclusion of this term as a random intercept resulted in a significantly worse model $(\triangle \mathrm{AIC}=4.8)$. The model was specified as:

MP burden $=\beta s$ (weight $)+s($ gut fullness $)+s($ age $)+$ $\mathrm{s}$ (reproductive phase $)+($ sea basin $)+\varepsilon$

The multicollinearity between the explanatory variables was evaluated using concurvity measures (Amodio et al., 2014) calculated by the $m g c v$-package and found to be low $(<0.24)$. Due to the overrepresentation of zeros in the data (overdispersion) for the MP burden, the model was constructed using zeroinflated Poisson error structure. Model performance was assessed using a quantile-quantile plot adapted for discrete data (Augustin et al., 2012) implemented in the package mgcViz (Figure S5). Differences in the MP burden between the basins were tested using Permanova with station nested within basin as a random factor (Anderson, 2001). The significance level was set at $\alpha=$ 0.05; all statistical analyses were conducted in R 3.5.0 ( $\mathrm{R}$ Core Team, 2014).

\section{Relationships Between HOCs and Ingested Microplastic}

Maximum-likelihood Factor Analysis with Varimax rotation (factanal function in base R) was used to assess the degree of association between the chemical variables and weight-specific MP burden in the GIT (objective 3). Whenever possible, the analysis was performed on an individual basis. When pooled samples were included, we used their arithmetic mean values. Prior to the analysis, Bartlett's test of sphericity was performed to confirm patterned relationship between the variables, which was statistically significant $\left(\chi_{15}^{2}=176, p<0.0001\right)$. A scree plot was used to determine the number of factors to retain, and factor loadings $>0.7$ were considered statistically significant (MacCallum et al., 2001). When measured HOC values were below the limit of quantification (LOQ), they were imputed by LOQ divided by the square root of two (Succop et al., 2004). The analyzed chemical concentrations were summed and grouped into their respective contaminant groups (PCBs, PBDEs, and organochlorine pesticides).
To test the robustness of the approach, we also performed a follow up analysis using Generalized Additive Models following the general model structure described in section Relationships between biological factors, geography and ingested microplastic. However, instead of using MP burden as the response variable, we modeled each HOC group individually and included weighted MP burden as an additional explanatory variable. The models were run using normal error structure and the response variable was transformed to conform to normality using either Log10 (PCBs), Box-Cox (BDE, $\mathrm{HBCD}$, and $\mathrm{HCB}$ ), or square root transformation (organochlorine pesticides, DD). Model fit was evaluated using residual plots.

\section{Modeling Plastic Ingestion by Herring}

To evaluate whether the observed MP burden could be predicted using ambient MP abundance data and food processing rates (objective 2), we modeled the ingestion of MP using literaturederived parameters on food uptake, egestion, and MP abundance in the study area. The rationale is that observed MP abundance in the gut would reflect average exposure levels assuming that (1) MP concentrations are fairly homogeneous in the outer coastal areas (Gorokhova, 2015; Gewert et al., 2017), which are the main feeding grounds of herring (Flinkman et al., 1998); (2) the MP abundance in the water column, where the fish feed, is similar to that at the surface, where the data on the relevant size fraction of MP (1-5 mm) were collected; (3) MP ingestion by herring is non-selective and thus proportional to the MP abundance in the water; and (4) gut evacuation rates are non-discriminatory, i.e., MP are egested at the same rate as prey remains. Then, the MP burden ( $\mathrm{MP}$ ind $^{-1}$ ) at any given time, $t$, can be written as the mass balance between the uptake and loss rates (Equation 1, Figure S2):

$$
M P_{t}=M P(t-d t)+(I R-E R) d t,
$$

where $I R$ and $E R$ are the ingestion and egestion rates $\left(\mathrm{MP} \mathrm{h}^{-1}\right)$, respectively. They can be calculated as:

$$
I R=C M P \times C R
$$

and

$$
E R=G E R \times M P_{t}
$$

where CMP is the ambient MP concentration (number of MP $\left.\mathrm{L}^{-1}\right), C R$ is the clearance rate $\left(\mathrm{L} \mathrm{h}^{-1}\right.$; the volume of water swept clear of particles per individual and hour), and GER is the gut evacuation rate $\left(\mathrm{h}^{-1}\right)$.

We used literature data to parameterize the model (Table S2). The MP concentrations in the target size range $(1-5 \mathrm{~mm})$ from surface waters in the outer Stockholm archipelago (Gewert et al., 2017) were used as CMP values. CR values were estimated using reported feeding rates for North Sea herring on Calanus finmarchicus, a copepod of similar size as the microplastics considered here, and the main prey for herring (Varpe and Fiksen, 2010); see Supporting Information 2.1 and Figure S3 for the calculation of CR. As published gut evacuation rates for 
TABLE 1 | Overview of the HOCs in herring muscle tissue and descriptive statistics of their concentrations ( $\mu \mathrm{g} \mathrm{g} \mathrm{g}^{-1}$ lipid weight).

\begin{tabular}{|c|c|c|c|c|c|c|c|c|}
\hline Chemical group & Chemical species & Abbreviation & Mean & SD & Median & Min & Max & LOQ \\
\hline \multirow[t]{7}{*}{ Polychlorinated biphenyls (PCBs) } & $2,4,4^{\prime}-\mathrm{PCB}$ & PCB 28 & 0.0039 & 0.0019 & 0.0033 & 0.0018 & 0.0106 & 0.002 \\
\hline & $2,2^{\prime}, 5,5^{\prime}-\mathrm{PCB}$ & PCB 52 & 0.0067 & 0.0044 & 0.0057 & 0.0025 & 0.0199 & 0.002 \\
\hline & $2,2^{\prime}, 4,5,5^{\prime}-\mathrm{PCB}$ & PCB 101 & 0.0222 & 0.0149 & 0.0176 & 0.0069 & 0.0713 & 0.002 \\
\hline & $2,3^{\prime}, 4,4^{\prime}, 5^{\prime}-\mathrm{PCB}$ & PCB 118 & 0.0204 & 0.0135 & 0.0155 & 0.0062 & 0.0694 & 0.002 \\
\hline & $2,2^{\prime}, 3,4,4^{\prime}, 5^{\prime}-\mathrm{PCB}$ & PCB 138 & 0.0591 & 0.0408 & 0.0444 & 0.0152 & 0.1896 & 0.002 \\
\hline & $2,2^{\prime}, 4,4^{\prime}, 5,5^{\prime}-\mathrm{PCB}$ & PCB 153 & 0.0417 & 0.0280 & 0.0345 & 0.0120 & 0.1320 & 0.002 \\
\hline & $2,2^{\prime}, 3,4,4^{\prime}, 5,5^{\prime}-\mathrm{PCB}$ & PCB 180 & 0.0181 & 0.0114 & 0.0149 & 0.0029 & 0.0551 & 0.002 \\
\hline \multirow[t]{6}{*}{ Organochlorine pesticides } & $4,4^{\prime}-\mathrm{DDT}$ & DDT & 0.0205 & 0.0218 & 0.0134 & 0.0037 & 0.0966 & 0.002 \\
\hline & 4,4'-DDE & DDE & 0.1055 & 0.0960 & 0.0815 & 0.0160 & 0.4130 & 0.002 \\
\hline & $4,4^{\prime}-\mathrm{DDD}$ & DDD & 0.0284 & 0.0333 & 0.0163 & 0.0016 & 0.1391 & 0.002 \\
\hline & $\alpha-1,2,3,4,5,6-$ Hexachlorocyclohexane & $\mathrm{AHCH}$ & 0.0029 & 0.0005 & 0.0030 & 0.0018 & 0.0039 & 0.002 \\
\hline & $\beta-1,2,3,4,5,6$-Hexachlorocyclohexane & $\mathrm{BHCH}$ & 0.0056 & 0.0027 & 0.0057 & 0.0018 & 0.0099 & 0.002 \\
\hline & $\gamma-1,2,3,4,5,6$-Hexachlorocyclohexane & Lindane & 0.0029 & 0.0005 & 0.0030 & 0.0018 & 0.0039 & 0.002 \\
\hline \multirow[t]{7}{*}{ Brominated flame retardants (BDEs) } & $2,4,4^{\prime}-$ TriBDE & BDE 28 & 0.0002 & 0.0001 & 0.0002 & 0.0001 & 0.0005 & 0.0002 \\
\hline & $2,2^{\prime}, 4,4^{\prime}$-TetraBDE & BDE 47 & 0.0051 & 0.0032 & 0.0041 & 0.0016 & 0.0160 & 0.0002 \\
\hline & $2,2^{\prime}, 4,4^{\prime}, 5$-PentaBDE & BDE 99 & 0.0012 & 0.0009 & 0.0009 & 0.0005 & 0.0044 & 0.0002 \\
\hline & $2,2^{\prime}, 4,4^{\prime}, 6-P e n t a B D E$ & BDE 100 & 0.0012 & 0.0007 & 0.0011 & 0.0004 & 0.0035 & 0.0002 \\
\hline & $2,2^{\prime}, 4,4^{\prime}, 5,5^{\prime}-$ HexaBDE & BDE 153 & 0.0002 & 0.0002 & 0.0002 & 0.0001 & 0.0009 & 0.0002 \\
\hline & $2,2^{\prime}, 4,4^{\prime}, 5,6^{\prime}-$ HexaBDE & BDE 154 & 0.0006 & 0.0004 & 0.0005 & 0.0002 & 0.0018 & 0.0002 \\
\hline & 1,2,5,6,9,10-Hexabromocyclododecane & HBCD & 0.0114 & 0.0096 & 0.0088 & 0.0025 & 0.0470 & 0.002 \\
\hline Other & Hexachlorobenzene & $\mathrm{HCB}$ & 0.0289 & 0.0209 & 0.0246 & 0.0114 & 0.1013 & 0.004 \\
\hline
\end{tabular}

$S D$, standard deviation; $L O Q$, the limit of quantification.

adult herring were not available, we used experimental values reported for other clupeids of similar size, European pilchard (Sardina pilchardus) (Costalago and Palomera, 2014) and South American pilchard (Sardinops sagax) (van der Lingen, 1998), which have similar feeding ecology and physiology as Baltic herring (Collard et al., 2017). The physiological rates used in the model corresponded to the average size of our fish.

The model was implemented using STELLA ${ }^{\circledR}$ ver. 9.4.1 software (iSee systems, Inc. Lebanon, NH, U.S.A.) to estimate MP burden ( $\mathrm{MP}$ ind ${ }^{-1}$ ) dynamics in a fish population at a given MP abundance. The intrapopulation variability was simulated using a Monte Carlo generator with 1,000 permutations; details on the simulation settings are provided in Supporting Information 2.2 and Figure S4. To validate the model, we compared the simulated data distribution from the model to the field data using descriptive statistics, $\chi^{2}$, and the two-sample Cramér-von Mises tests.

\section{RESULTS}

\section{Observed MP Burden}

Particles identified by visual inspection as MP (the frequency of occurrence, $\%$ FO, Table 2) were found in 44 out of the 130 individuals (33.8\%; range: $1-51$ pieces of putative plastic fibers or fragments ind $\left.{ }^{-1}\right)$. In these 44 individuals, the mean abundance

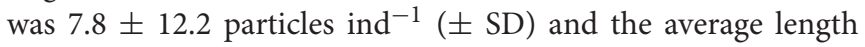
of the MP was $2.39 \pm 1.80 \mathrm{~mm}$; width was $0.022 \pm 0.10 \mathrm{~mm}$ ( \pm SD, all measured MP were fibers). The dominant type of particles were fibers of various colors $(87.6 \%)$, while fragments were less frequent (12.4\%). However, only $32.8 \%$ of the visually identified, putative MP were classified as either synthetic or semisynthetic (viscose) by FTIR and $47.5 \%$ were classified as being of natural origin (e.g., chitin, fur, and cellulose); 19.7\% could not be identified (Table S1).

After correcting for the proportion of misclassified samples, only 29 individuals containing MP were retained (22\%; range: 1 to $17 \mathrm{MP}$ ), with a mean abundance of $3.9 \mathrm{MP}^{-1} \mathrm{ind}^{-1} \pm 4.4 \mathrm{SD}$. When all examined individuals were considered, the population average was $0.9 \mathrm{MP}$ ind $^{-1} \pm 2.6 \mathrm{SD}$, with the $95 \%$ bootstrap confidence interval ranging $0.5-1.4 \mathrm{MP}$ ind $^{-1}$. The variation in the MP burden between the stations and basins was high (Figure 2; Table 2) and no significant differences in the MP burden between the basins were found (station nested within basin as a random factor, pseudo $\left.F_{(4,117)}=0.9, p=0.48\right)$.

\section{Predicted vs. Observed MP Burden and Frequency of Occurrence}

The model predicted that $81 \%$ of fish contained MP, with a mean MP burden of $4.7 \mathrm{MP}$ ind $^{-1}$; these values were about 5-fold the observed values. However, the ranges of the frequency distributions for the simulated and observed values were overlapping, although the field observations were more strongly skewed toward zero values compared to the model prediction (Figure 3A; Table S3). The difference between the distributions was statistically significant (Cramér-von Mises $T$ $=226, p<0.0001$ ). However, when zero values were excluded, the distributions, albeit still significantly different (Cramér-von 


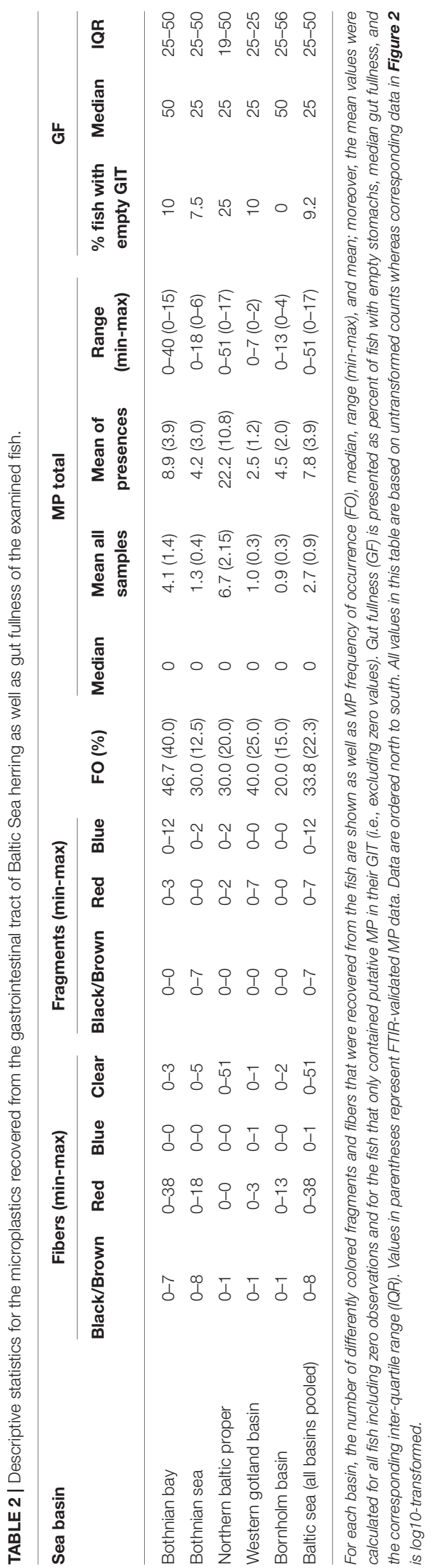

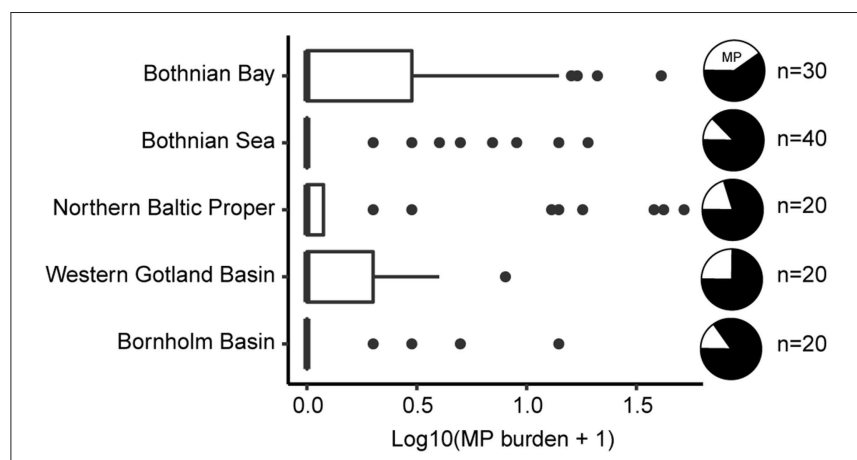

FIGURE 2 | Boxplot of $\log _{10}$-transformed MP abundance in the gastrointestinal tract (GIT) of herring per basin; the basins are ordered from north to south. Data are presented as medians (vertical lines), inter quartile range, IQR (boxes), 1.5 IQR (whiskers) and outliers (points) deviating > 1.5 IQR. The black slices of the pie charts indicate the proportion of the fish with no MP in the GIT. Corresponding, untransformed data is provided in Table 2.
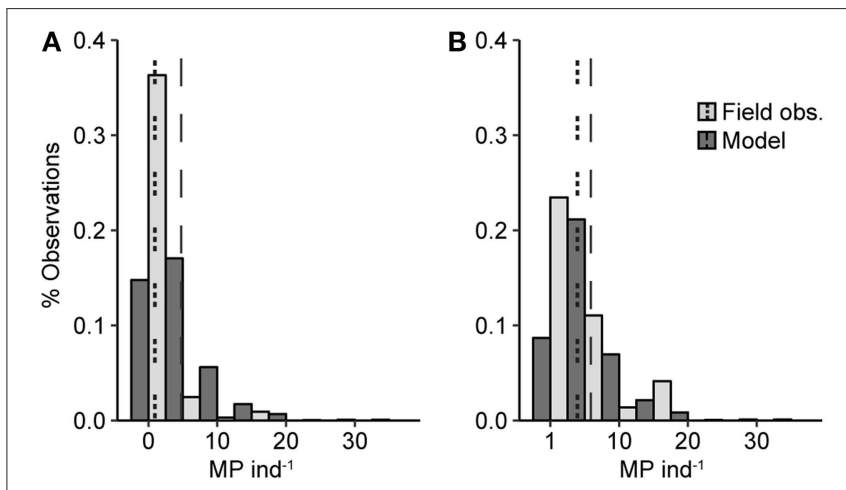

FIGURE 3 | Frequency distribution of the MP burden based on the model simulations (dark gray bars) and field observations (light gray bars). (A) shows the entire dataset and $\mathbf{( B )}$ presents only fish with MP in the GIT (i.e., the non-zero values). The dashed vertical lines indicate the mean values for the model simulations (long dash) and the observations (short dash).

Mises $T=12.5, p<0.01$ ), became more similar (Figure 3B; Table S3), indicating that much of the difference between the distributions was driven by the significantly higher proportion of zero observations in the field data $\left(\chi^{2}=219.5, p<0.0001\right)$.

\section{Linkage Between MP Intake and HOCs}

We found no relationship between the weight-specific MP burden and the concentration of any of the HOCs (Figure 4). Together, the two factors explained a cumulative variance of 84.3\% (Table S5). As a variable, weight-specific MP burden loaded weakly and negatively $(-0.14)$ on the first axis and moderately positive (0.58) on the second axis. In contrast, the organochlorine pesticides and PBDEs loaded significantly and positively on the first axis, while the PCBs loaded moderately positive (0.56) on the first and significantly positive (0.82) on the second axis. Hence, no contaminant group had loadings clustering with those for the weight-specific MP burden. The follow-up GAM analysis confirmed the lack of any significant 


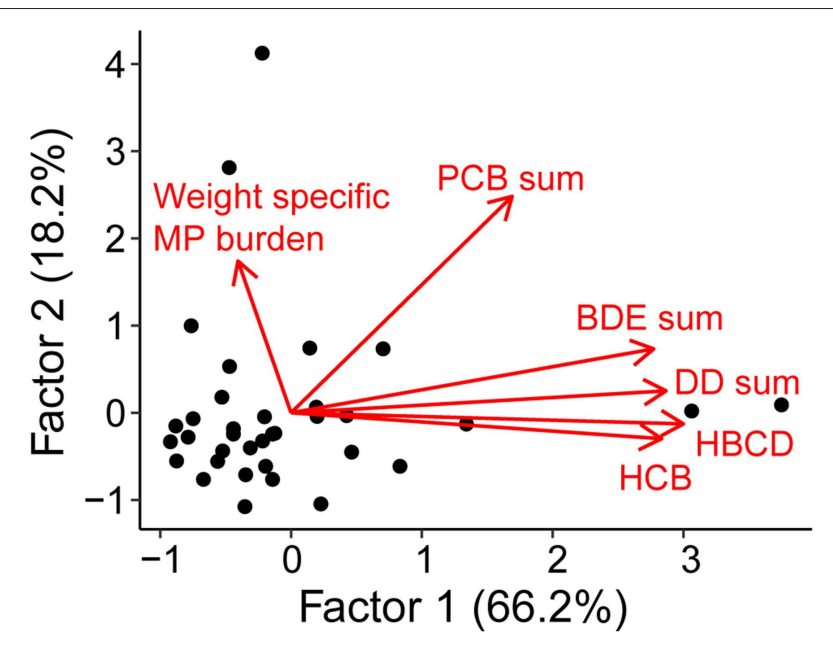

FIGURE 4 | Factor scores (axes) and loadings (arrows) of contaminants (HBCD, HCB and the sum of PCBs, BDEs, and DDs) and weight-specific MP burden. The data included in this analysis were weighted MP burden and $\mathrm{HOC}$ concentrations in herring muscle tissue determined in (1) individual fish specimens, and (2) pooled fish samples (10 ind. per sample).

relations between $\mathrm{MP}$ and $\mathrm{HOC}$ groups (PCBs, BDEs, DDs, HBCD, and HCB, Table S6 and Figure S6).

\section{Biological Factors Related to MP Burden}

The GAM explained $64.7 \%$ of the deviance (Table S4) and indicated that the MP burden was positively and nearly linearly related to fish body weight (GAM, $\chi^{2}=16.8, p<$ 0.001 , Figure 5A). In contrast, a negative effect was found for reproductive phase, where MP burden was significantly lower in fish that had reached sexual maturity $\left(\mathrm{GAM} \chi^{2}=11.1, p<0.05\right.$, Figure 5B). Gut fullness only had a negative effect on MP burden when the GIT was empty of food items (GAM $\chi^{2}=41.3, p<$ 0.0001, Figure 5C), while Age displayed a negative relationships with MP burden (GAM $\chi^{2}=18.8, p<0.0001$, Figure 5D).

\section{DISCUSSION}

\section{Microplastics Are Common but Not Abundant in Herring Guts}

Microplastics (mostly fibers of synthetic and semi-synthetic origin) were found in about $20 \%$ of the fish. While these values are in good agreement with those reported for herring by Beer et al. (2018) for the central Baltic Sea (i.e., 20\% containing MP, with $93 \%$ fibers), other studies report considerably lower MP frequency of occurrence and fiber contribution to total MP in herring. Both Foekema et al. (2013) and Rummel et al. (2016) found plastics in only $2 \%$ of herring samples from the North Sea and the Southern Baltic Sea, with fibers accounting for $<10 \%$ of MP. Excluding fibers from their analyses, Budimir et al. (2018) reported a frequency of occurrence as low as $1.8 \%$ in herring from the northern Baltic Sea. Our results suggest that these discrepancies between different studies could be related to differences in fish size, gut fullness and ontogenetic diet shifts. For example, Foekema et al. (2013) used fish that were considerably larger (>200 mm total length) and most likely already had switched from filter feeding to raptorial feeding on larger prey (Huse and Toresen, 1996). This change in feeding mode would result in a lower ingestion rate of zooplanktonsized plastic particles and thus in a lower overall MP burden. In the study of Rummel et al. (2016), many fish stomachs were empty, which probably was related to arrested feeding in concert with spawning (Stacey and Hourston, 1982), and possibly, stressinduced gut evacuation caused by the fish sampling (Wilkins, 1967; Vinson and Angradi, 2011). In addition, one would expect the amount of ingested MP to scale with the absolute size of bolus or gut fullness. However, since this relationship was weak (Figure 5C), our findings only partly support this expectation. One possible explanation for this could be a slower egestion of MP compared to prey, similar to the selective retention of plastic fibers in amphipods (Au et al., 2015) and fragments in cladocerans (Ogonowski et al., 2016). The slower egestion would result in a temporary accumulation of MP in the fish gut and obscure the expected positive relationship between the gut fullness and MP burden. While fish weight appears to be the strongest co-variable for standardizing gut MP content, gut fullness was also influential, particularly for fish with empty guts, which may occur during fasting periods that are normally observed during spawning time (Stacey and Hourston, 1982). The latter was further supported by the negative effect of reproductive phase on MP burden. Although the effect of Age also was statistically significant, the effect was not particularly strong and most probably of lesser biological importance.

The range of the MP burden predicted by our simple model was similar to that observed in the field-caught specimens, although the proportion of fish predicted to contain MP was more than 5-fold higher (Figure 3A). This is, however, not surprising because, the frequency of zero values was driven by the variability in MP occurrence in the water that was derived from surface-collected MP. Moreover, the model assumed homogeneous MP distribution in the water column, which is unlikely, because the MP distribution is patchy, varying with depth (Gorokhova, 2015). In addition, MP can form aggregates that are too large to be mistaken for zooplankton prey (Lagarde et al., 2016). Therefore, the distribution of MP concentrations originating from the surface collections and used to model MP encounter rate might poorly reflect the actual abundance of MP available to the fish. The observed MP burden for the population was also more variable, which is likely to be related to diel variations in feeding and gut evacuation under natural conditions (Seyhan and Grove, 2003), not accounted for by the model. Other biological factors, such as maturity level, ontogenetic changes in feeding, and behavior, may have affected the probability of MP ingestion and thus contributed to the intrapopulation variability in the MP burden. Finally, fishing methods (which may induce spontaneous gut evacuation) and time of capture (which may reflect diurnal differences in feeding activity) may have contributed to the observed discrepancy in the MP burden distribution. Nevertheless, given the simplicity of the model and the uncertainties associated with its parameters, the predicted values were sufficiently close to those found in the field, indicating that MP uptake can be predicted provided that we have reliable MP abundance estimates. 

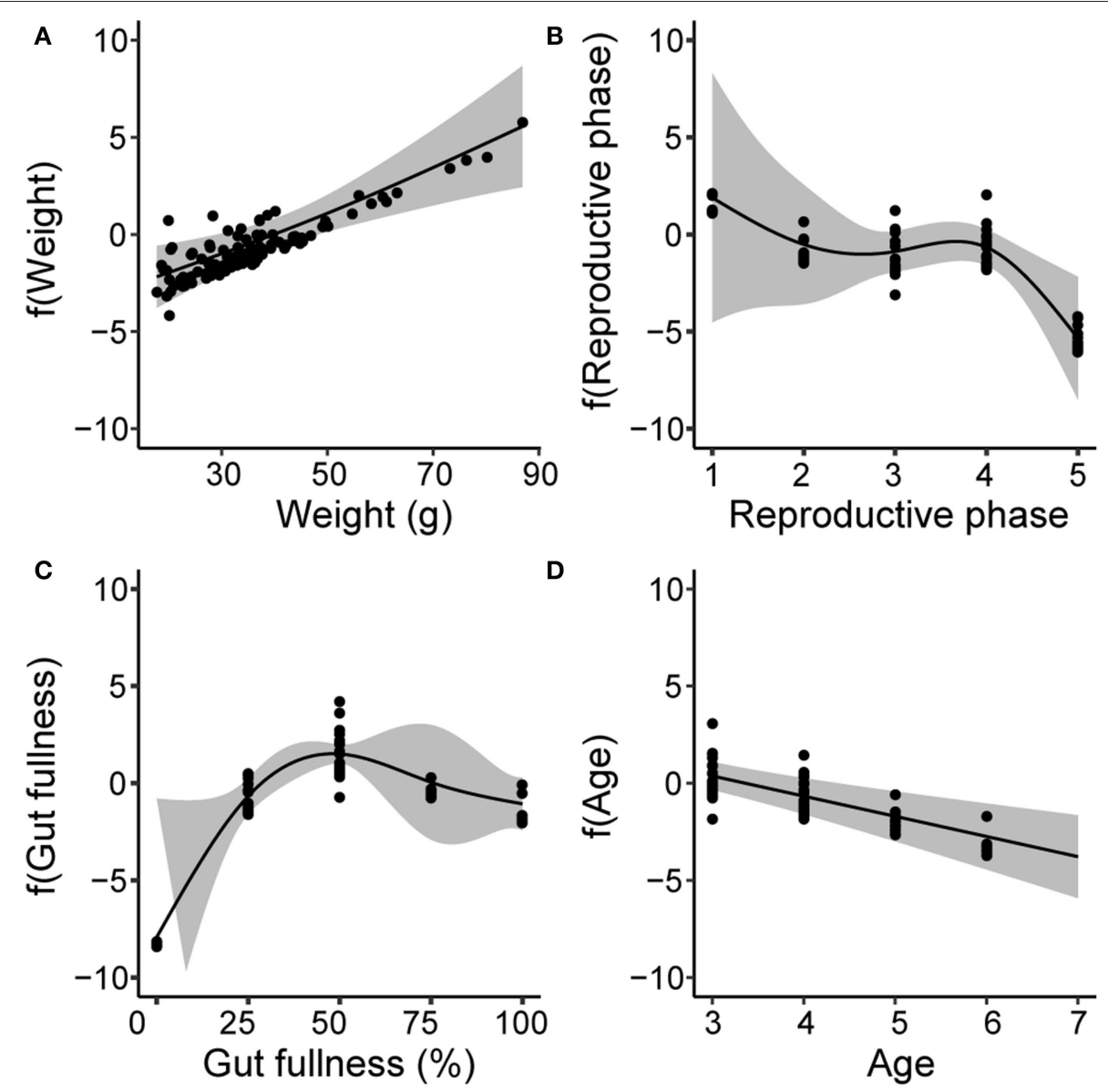

FIGURE 5 | Generalized additive models (GAMs) showing partial response curves for the explanatory biological variables: body weight (A), reproductive phase (B), gut fullness (C) and age (D). The classes for reproductive phase correspond to: $1=$ deformed gonads, $2=$ post spawned, $3=$ juvenile, $4=$ developing gonads, and $5=$ mature gonads. The vertical axis shows the relative influence of the explanatory variable on the prediction of MP burden on the base of partial residuals. Gray bands indicate $95 \%$ confidence interval for each curve.

\section{No Correlation Between Weight-Specific MP Burden and HOCs}

The transfer of hydrophobic contaminants from ingested plastics to biota has been described as the so-called "Trojan horse" effect (Cole et al., 2011). While this transfer has been demonstrated under laboratory conditions (Besseling et al., 2013; Batel et al., 2016), recent modeling studies indicate that natural sources are much more important than MP in explaining HOC bioaccumulation patterns in aquatic organisms (Mohamed Nor and Koelmans, 2019). We did not find any correlation between HOC concentrations in herring muscle and MP burden. It could be argued, however, that omitting small MP $(<1 \mathrm{~mm})$ from our analysis, could have biased the results. Indeed, by focusing on the larger MP, we ignored the potentially important influence of a higher total surface area and thus higher HOC desorption rates (Hendriks et al., 2001; Hartmann et al., 2017) of smaller plastic fragments. From the fish feeding biology point of view, however, the ingestion of such small particles by fish of this size is rather unlikely, because filter-feeding herring have a relatively low capacity to retain small particles due to their rather wide gill raker spacing (Collard et al., 2017) and actively avoid smaller prey by raptorial feeding (Aro et al., 1989). This line of reasoning has also been supported by several other studies reporting a predominant retention of larger than 1-mm MP by herring of similar size as in our study (Lenz et al., 2016; Collard et al., 2017; Beer et al., 2018). In the European pilchard (Sardina pilchardus), Digka et al. (2018) analyzed the presence of anthropogenic microparticles $(1.2-5,000 \mu \mathrm{m})$ in the fishes' gastrointestinal tract using hydrogen peroxide digestion and found $\sim 75 \%$ of the particles to be in the size range of the natural food, further supporting primary ingestion as the main route for microplastic uptake in clupeids. Moreover, given the short residence time (Grigorakis et al., 2017) of ingested particles and the slow desorption kinetics of many HOCs, the lack of correlation between the MP and organic contaminants is rather expected and in line with other reports for fish and other aquatic animals (Herzke et al., 2016; Kleinteich et al., 2018; Gerdes et al., 2019).

Causality is difficult to prove using environmental samples, where many different parameters concurrently 
affect contaminant body burden of an organism (Hartmann et al., 2017), including various biotic factors that have significant effects on both MP (this study) and HOC levels (Persson et al., 2013). However, our findings suggest that there is no tenable relationship between the MP intake and tissue contaminant concentrations in the Baltic herring (Figure 4). Similarly, no correlation has been found between the amount of ingested plastic and HOC concentrations in northern fulmars (Fulmarus glacialis) from the Norwegian coast (Herzke et al., 2016), even though the birds had ingested much larger amounts of plastic and their gut passage time for plastic debris is several orders of magnitude longer than in herring (Ryan, 2015). This lack of relationship is also supported by the relatively constant MP burden observed in Baltic herring over the past three decades (Beer et al., 2018), while muscle concentrations of HOCs have decreased significantly (Bignert et al., 2016). The mass-balance model indicates that our measurements of the MP burden are ecologically plausible given the currently reported abundances of MP in the Baltic surface water, thus supporting the reliability of the MP burden estimates in the Baltic herring reported here and in other studies and providing confidence in the methods employed. Taken together, these findings contrast the currently held paradigm that microplastics are an important source and vector of HOCs for aquatic organisms (Mato et al., 2001; Rochman et al., 2013).

\section{CONCLUSIONS}

Our findings suggest that in a semi-enclosed sea like the Baltic, where the MP loading is expectedly high, the frequency of occurrence of microplastic in planktivorous fish is moderate. In agreement with other studies, we also found that biological factors, such as fish size and the reproductive state may affect both feeding in general and selectivity toward MP, and, hence, the MP burden. However, we found no indication that HOC concentrations in the muscle tissue are related to the amount of ingested plastic in the fish. Thus, our study further strengthens the view that MP contribute extremely little to the herring diet and play a negligible role in explaining contaminant bioaccumulation in the fish.

\section{DATA AVAILABILITY}

The datasets generated for this study are available on request to the corresponding author.

\section{REFERENCES}

Amodio, S., Aria, M., and D'Ambrosio, A. (2014). On concurvity in non-linear and non-parametric regression models. Statistica 74, 85-98. doi: 10.6092/issn.1973-2201/4599

Anderson, M. J. (2001). A new method for non-parametric multivariate analysis of variance. Austral Ecol. 26, 32-46. doi: 10.1111/j.1442-9993.2001.01070.pp.x

\section{ETHICS STATEMENT}

All applicable international, national, and/or institutional guidelines for the care and use of animals were followed. The fish caught for this study were collected under license N83/14 and complied with the standards and procedures stipulated by the Swedish Ministry of Agriculture.

\section{AUTHOR CONTRIBUTIONS}

EG conceived the study. MO and EG conducted the data analysis and were mainly responsible for manuscript writing. VW performed the microplastic extraction from fish guts and performed the primary visual microplastic identification. SD coordinated the fish sampling, provided the gastrointestinal tracts from herring and was responsible the HOC chemical analyses. $\mathrm{AB}$ and $\mathrm{EH}-\mathrm{B}$ performed the FTIR-analyses and contributed to manuscript writing.

\section{FUNDING}

This work was supported through the Joint Programming Initiative Healthy and Productive Seas and Oceans (JPI-Oceans) WEATHER-MIC project by the Swedish Research Council for Environment, Agricultural Sciences and Spatial Planning (FORMAS) [Grant No. 942-2015-1866], FORMAS project; irPLAST [Grant No. 2015-932], through BONUS MICROPOLL project by BONUS (Art 185), funded jointly by the EU and the Swedish Innovation Agency VINNOVA [Grant No. 2017-00979] as well as the Baltic Ecosystem Adaptive Management (BEAM) project. The study was designed, analyzed, and compiled solely at the responsibility of the authors without the involvement of the funding agencies.

\section{ACKNOWLEDGMENTS}

Preliminary results from this study were presented at the 15th International Conference on Environmental Science and Technology in 2017, Rhodes, Greece, paper number: CEST2017_00690. A preprint of this manuscript has been deposited in BioRxiv; https://doi.org/10.1101/363127.

\section{SUPPLEMENTARY MATERIAL}

The Supplementary Material for this article can be found online at: https://www.frontiersin.org/articles/10.3389/fenvs. 2019.00134/full\#supplementary-material

Aro, E., Vuorinen, I., and Flinkman, J. (1989). The Prey Preference of Baltic Herring in the Northern Baltic Sea. Copenhagen: International Counc. for the Exploration of the Sea.

Au, S. Y., Bruce, T. F., Bridges, W. C., and Klaine, S. J. (2015). Responses of Hyalella azteca to acute and chronic microplastic exposures: effects of microplastic exposure on Hyalella azteca. Environ. Toxicol. Chem. 34, 25642572. doi: 10.1002/etc.3093 
Augustin, N., Sauleau, E.-A., and Wood, S. (2012). On quantilequantile plots for generalized linear models. Compute. Stat. Data Anal. 56, 2404-2409. doi: 10.1016/j.csda.2012. 01.026

Batel, A., Linti, F., Scherer, M., Erdinger, L., and Braunbeck, T. (2016). Transfer of benzo[a]pyrene from microplastics to Artemia nauplii and further to zebrafish via a trophic food web experiment: CYP1A induction and visual tracking of persistent organic pollutants. Environ. Toxicol. Chem. 35, 1656-1666. doi: $10.1002 /$ etc. 3361

Beer, S., Garm, A., Huwer, B., Dierking, J., and Nielsen, T. G. (2018). No increase in marine microplastic concentration over the last three decades - A case study from the Baltic Sea. Sci. Total Environ. 621, 1272-1279. doi: $10.1016 /$ j.scitotenv.2017.10.101

Besseling, E., Wegner, A., Foekema, E. M., van den Heuvel-Greve, M. J., and Koelmans, A. A. (2013). Effects of microplastic on fitness and PCB bioaccumulation by the Lugworm Arenicola marina (L.). Environ. Sci. Technol. 47, 593-600. doi: 10.1021/es302763x

Bignert, A., Danielsson, S., Faxneld, S., and Nyberg, E. (2016). Comments Concerning the National Swedish Contaminant Monitoring Programme in Marine Biota. Stockholm.

Bucholtz, R. H., Tomkiewicz, J., and Dalskov, J. (2008). Manual to Determine Gonadal Maturity of Herring (Clupea harengus L. ). Charlottenlund: National Institute of Aquatic Resources.

Budimir, S., Setälä, O., and Lehtiniemi, M. (2018). Effective and easy to use extraction method shows low numbers of microplastics in offshore planktivorous fish from the northern Baltic Sea. Mar. Pollut. Bull. 127, 586-592. doi: 10.1016/j.marpolbul.2017.12.054

Cole, M., Lindeque, P., Fileman, E., Halsband, C., and Galloway, T. S. (2015). The impact of polystyrene microplastics on feeding, function and fecundity in the marine copepod calanus helgolandicus. Environ. Sci. Technol. 49, 1130-1137. doi: $10.1021 /$ es504525u

Cole, M., Lindeque, P., Fileman, E., Halsband, C., Goodhead, R., Moger, J., et al. (2013). Microplastic ingestion by zooplankton. Environ. Sci. Technol. 47, 6646-6655. doi: 10.1021/es400663f

Cole, M., Lindeque, P., Halsband, C., and Galloway, T. S. (2011). Microplastics as contaminants in the marine environment: a review. Mar. Pollut. Bull. 62, 2588-2597. doi: 10.1016/j.marpolbul.2011.09.025

Collard, F., Gilbert, B., Eppe, G., Roos, L., Compère, P., Das, K., et al. (2017). Morphology of the filtration apparatus of three planktivorous fishes and relation with ingested anthropogenic particles. Mar. Pollut. Bull. 116, 182-191. doi: 10.1016/j.marpolbul.2016.12.067

Costalago, D., and Palomera, I. (2014). Feeding of European pilchard (Sardina pilchardus) in the northwestern Mediterranean: from late larvae to adults. Sci. Mar. 78, 41-54. doi: 10.3989/scimar.03898.06D

Dehaut, A., Cassone, A.-L., Frère, L., Hermabessiere, L., Himber, C., Rinnert, E., et al. (2016). Microplastics in seafood: benchmark protocol for their extraction and characterization. Environ. Pollut. 215, 223-233. doi: 10.1016/j.envpol.2016.05.018

Digka, N., Tsangaris, C., Torre, M., Anastasopoulou, A., and Zeri, C. (2018). Microplastics in mussels and fish from the Northern Ionian Sea. Mar. Pollut. Bull. 135, 30-40. doi: 10.1016/j.marpolbul,0.2018.06.063

EFSA Panel on Contaminants in the Food Chain (CONTAM) (2016). Presence of microplastics and nanoplastics in food, with particular focus on seafood. EFSA J. 14, n/a-n/a. doi: 10.2903/j.efsa.2016.4501

Flinkman, J., Aro, E., Vuorinen, I., and Viitasalo, M. (1998). Changes in northern Baltic zooplankton and herring nutrition from 1980s to 1990s: topdown and bottom-up processes at work. Mar. Ecol. Prog. Ser. 165, 127-136. doi: $10.3354 /$ meps 165127

Foekema, E. M., De Gruijter, C., Mergia, M. T., van Franeker, J. A., Murk, A. J., and Koelmans, A. A. (2013). Plastic in North sea fish. Environ. Sci. Technol. 47, 8818-8824. doi: 10.1021/es400931b

Gerdes, Z., Ogonowski, M., Nybom, I., Ek, C., Adolfsson-Erici, M., Barth, A., et al. (2019). Microplastic-mediated transport of PCBs? A depuration study with Daphnia magna. PLoS ONE 14:e0205378. doi: 10.1371/journal.pone.0205378

Gewert, B., Ogonowski, M., Barth, A., and MacLeod, M. (2017). Abundance and composition of near surface microplastics and plastic debris in the Stockholm Archipelago, Baltic Sea. Mar. Pollut. Bull. 120, 292-302. doi: 10.1016/j.marpolbul.2017.04.062
Gorokhova, E. (2015). Screening for microplastic particles in plankton samples: how to integrate marine litter assessment into existing monitoring programs? Mar. Pollut. Bull. 99, 271-275. doi: 10.1016/j.marpolbul.2015.07.056

Gouin, T., Roche, N., Lohmann, R., and Hodges, G. (2011). A thermodynamic approach for assessing the environmental exposure of chemicals absorbed to microplastic. Environ. Sci. Technol. 45, 1466-1472. doi: 10.1021/es1032025

Grigorakis, S., Mason, S. A., and Drouillard, K. G. (2017). Determination of the gut retention of plastic microbeads and microfibers in goldfish (Carassius auratus). Chemosphere 169, 233-238. doi: 10.1016/j.chemosphere.2016.11.055

Hartmann, N. B., Rist, S., Bodin, J., Jensen, L. H., Schmidt, S. N., Mayer, P., et al. (2017). Microplastics as vectors for environmental contaminants: exploring sorption, desorption, and transfer to biota. Integr. Environ. Assess. Manag. 13, 488-493. doi: 10.1002/ieam. 1904

Hendriks, A. J., van der Linde, A., Cornelissen, G., and Sijm, D. T. H. M. (2001). The power of size. 1. Rate constants and equilibrium ratios for accumulation of organic substances related to octanol-water partition ratio and species weight. Environ. Toxicol. Chem. 20, 1399-1420. doi: 10.1002/etc.5620200703

Hermsen, E., Mintenig, S. M., Besseling, E., and Koelmans, A. A. (2018). Quality criteria for the analysis of microplastic in biota samples: a critical review. Environ. Sci. Technol. 52, 10230-10240. doi: 10.1021/acs.est.8b01611

Herzke, D., Anker-Nilssen, T., Nøst, T. H., Götsch, A., Christensen-Dalsgaard, S., Langset, M., et al. (2016). Negligible impact of ingested microplastics on tissue concentrations of persistent organic pollutants in northern fulmars off coastal norway. Environ. Sci. Technol. 50, 1924-1933. doi: 10.1021/acs.est.5b04663

Hidalgo-Ruz, V., Gutow, L., Thompson, R. C., and Thiel, M. (2012). Microplastics in the marine environment: a review of the methods used for identification and quantification. Environ. Sci. Technol. 46, 3060-3075. doi: 10.1021/es20 31505

Huse, G., and Toresen, R. (1996). A comparative study of the feeding habits of herring (Clupea harengus, Clupeidae, 1.) and capelin (Mallotus villosus, Osmeridae, müller) in the barents sea. Sarsia 81, 143-153. doi: $10.1080 / 00364827.1996 .10413618$

Jovanović, B. (2017). Ingestion of microplastics by fish and its potential consequences from a physical perspective. Integr. Environ. Assess. Manag. 13, 510-515. doi: 10.1002/ieam.1913

Kleinteich, J., Seidensticker, S., Marggrander, N., and Zarfl, C. (2018) Microplastics reduce short-term effects of environmental contaminants. Part II: polyethylene particles decrease the effect of polycyclic aromatic hydrocarbons on microorganisms. Int. J. Environ. Res. Public Health 15:287. doi: 10.3390/ijerph15020287

Lagarde, F., Olivier, O., Zanella, M., Daniel, P., Hiard, S., and Caruso, A. (2016). Microplastic interactions with freshwater microalgae: hetero-aggregation and changes in plastic density appear strongly dependent on polymer type. Environ. Pollut. 215, 331-339. doi: 10.1016/j.envpol.2016.05.006

Lenz, R., Enders, K., Kirk Sørensen, T., and Stedmon, C. A. (2016). Analysis of Microplastic in the Stomachs of Herring and Cod From the North Sea and Baltic Sea. Copenhagen, Denmark: DTU Aqua National Institute of Aquatic Resources. Available online at: https://www.researchgate.net/publication/ 302423216_Analysis_of_microplastic_in_the_stomachs_of_herring_and_ cod_from_the_North_Sea_and_Baltic_Sea (accessed June 26, 2018).

Lusher, A. L., Hernandez-Milian, G., O’Brien, J., Berrow, S., O'Connor, I., and Officer, R. (2015). Microplastic and macroplastic ingestion by a deep diving, oceanic cetacean: the True's beaked whale Mesoplodon mirus. Environ. Pollut. 199, 185-191. doi: 10.1016/j.envpol.2015.01.023

Lusher, A. L., McHugh, M., and Thompson, R. C. (2013). Occurrence of microplastics in the gastrointestinal tract of pelagic and demersal fish from the English Channel. Mar. Pollut. Bull. 67, 94-99. doi: 10.1016/j.marpolbul.2012.11.028

MacCallum, R. C., Widaman, K. F., Preacher, K. J., and Hong, S. (2001). Sample size in factor analysis: the role of model error. Multivariate Behav. Res. 36, 611-637. doi: 10.1207/S15327906MBR3604_06

Markic, A., Gaertner, J.-C., Gaertner-Mazouni, N., and Koelmans, A. A. (2019). Plastic ingestion by marine fish in the wild. Crit. Rev. Environ. Sci. Technol. 1-41. doi: 10.1080/10643389.2019.1631990

Mato, Y., Isobe, T., Takada, H., Kanehiro, H., Ohtake, C., and Kaminuma, T. (2001). Plastic resin pellets as a transport medium for toxic chemicals in the marine environment. Environ. Sci. Technol. 35, 318-324. doi: $10.1021 /$ es 0010498 
Mohamed Nor, N. H., and Koelmans, A. A. (2019). Transfer of PCBs from microplastics under simulated gut fluid conditions is biphasic and reversible. Environ. Sci. Technol. 53, 1874-1883. doi: 10.1021/acs.est.8b05143

Ogonowski, M., Schür, C., Jarsén, Å., and Gorokhova, E. (2016). The effects of natural and anthropogenic microparticles on individual fitness in daphnia magna. PLoS ONE 11:e0155063. doi: 10.1371/journal.pone.0155063

Persson, S., Rotander, A., van Bavel, B., Brunström, B., Bäcklin, B.-M., and Magnusson, U. (2013). Influence of age, season, body condition and geographical area on concentrations of chlorinated and brominated contaminants in wild mink (Neovison vison) in Sweden. Chemosphere 90, 1664-1671. doi: 10.1016/j.chemosphere.2012.09.060

Primpke, S., Wirth, M., Lorenz, C., and Gerdts, G. (2018). Reference database design for the automated analysis of microplastic samples based on Fourier transform infrared (FTIR) spectroscopy. Anal. Bioanal. Chem. 410, 5131-5141. doi: 10.1007/s00216-018-1156-x,

R Core Team (2014). R: A Language and Environment for Statistical Computing. Vienna: R Foundation for Statistical Computing. Available online at: http:// www.R-project.org/ (accessed September 3, 2019).

Rochman, C. M., Hoh, E., Kurobe, T., and Teh, S. J. (2013). Ingested plastic transfers hazardous chemicals to fish and induces hepatic stress. Sci. Rep. 3:3263. doi: $10.1038 /$ srep03263

Rochman, C. M., Lewison, R. L., Eriksen, M., Allen, H., Cook, A.-M., and Teh, S. J. (2014). Polybrominated diphenyl ethers (PBDEs) in fish tissue may be an indicator of plastic contamination in marine habitats. Sci. Total Environ. 476-477, 622-633. doi: 10.1016/j.scitotenv.2014.01.058

Rummel, C. D., Löder, M. G. J., Fricke, N. F., Lang, T., Griebeler, E.M., Janke, M., et al. (2016). Plastic ingestion by pelagic and demersal fish from the North Sea and Baltic Sea. Mar. Pollut. Bull. 102, 134-141. doi: 10.1016/j.marpolbul.2015.11.043

Ryan, P. G. (2015). How quickly do albatrosses and petrels digest plastic particles? Environ. Pollut. 207, 438-440. doi: 10.1016/j.envpol.2015.08.005

Schneider, C. A., Rasband, W. S., and Eliceiri, K. W. (2012). NIH Image to ImageJ: 25 years of image analysis. Nat. Meth. 9, 671-675. doi: 10.1038/nmeth.2089

Seyhan, K., and Grove, D. J. (2003). A new approach in modelling gastric emptying in fish. Turk. J. Vet. Anim. Sci. 27, 1043-1047.

Stacey, N. E., and Hourston, A. S. (1982). Spawning and feeding behavior of captive pacific herring, Clupea harengus pallasi. Canad. J. Fish. Aquat. Sci. 39, 489-498. doi: 10.1139/f82-067

Succop, P. A., Clark, S., Chen, M., and Galke, W. (2004). Imputation of data values that are less than a detection limit. J. Occup. Environ. Hyg. 1, 436-441. doi: 10.1080/15459620490462797
TemaNord (1995). Nordic Environmental Specimen Banking: Methods in Use in ESB: Manual for Nordic Countries. Copenhagen: TemaNord Scandinavia; Nordic Council of Ministers.

Thompson, R. C., Olsen, Y., Mitchell, R. P., Davis, A., Rowland, S. J., John, A. W. G., et al. (2004). Lost at sea: where is all the plastic? Science 304, 838-838. doi: 10.1126/science.1094559

van der Lingen, C. D. (1998). Gastric evacuation, feeding periodicity and daily ration of sardine Sardinops sagax in the southern Benguela upwelling ecosystem. South Afr. J. Mar. Sci. 19, 305-316. doi: 10.2989/0257761987841 26791

Varpe, Ø., and Fiksen, Ø. (2010). Seasonal plankton-fish interactions: light regime, prey phenology, and herring foraging. Ecology 91, 311-318. doi: 10.1890/08-1817.1

Vinson, M. R., and Angradi, T. R. (2011). Stomach emptiness in fishes: sources of variation and study design implications. Rev. Fish. Sci. 19, 63-73. doi: $10.1080 / 10641262.2010 .536856$

Wardrop, P., Shimeta, J., Nugegoda, D., Morrison, P. D., Miranda, A., Tang, M., et al. (2016). Chemical pollutants sorbed to ingested microbeads from personal care products accumulate in fish. Environ. Sci. Technol. 50, 4037-4044. doi: 10.1021/acs.est.5b06280

Wesch, C., Bredimus, K., Paulus, M., and Klein, R. (2016). Towards the suitable monitoring of ingestion of microplastics by marine biota: a review. Environ. Pollut. 218, 1200-1208. doi: 10.1016/j.envpol.2016. 08.076

Wilkins, N. P. (1967). Starvation of the herring, Clupea harengus L.: Survival and some gross biochemical changes. Comp. Biochem. Physiol. 23, 503-518. doi: 10.1016/0010-406X(67) 90402-1

Conflict of Interest Statement: The authors declare that the research was conducted in the absence of any commercial or financial relationships that could be construed as a potential conflict of interest.

Copyright (c) 2019 Ogonowski, Wenman, Barth, Hamacher-Barth, Danielsson and Gorokhova. This is an open-access article distributed under the terms of the Creative Commons Attribution License (CC BY). The use, distribution or reproduction in other forums is permitted, provided the original author(s) and the copyright owner(s) are credited and that the original publication in this journal is cited, in accordance with accepted academic practice. No use, distribution or reproduction is permitted which does not comply with these terms. 